\title{
Yürüme analizindeki yenilikler
}

\section{Recent advances in gait analysis}

\author{
Fuat Bilgili, Cansu Sardoğan \\ İstanbul Üniversitesi İstanbul Tıp Fakültesi, Ortopedi ve Travmatoloji Ana Bilim Dalı, İstanbul
}

Yürüme analizinde (YA) hem klinik hem de teknolojik yönden yenilikler yaşanmaktadır. Üç boyutlu yürüme analizinde belirli ölçütlerin değerlendirilmesine yönelik çok sayıda veri ve grafik üretilmektedir. Bu durum bir taraftan değerlendirmenin objektifliğini artırırken diğer taraftan değerlendirmeyi daha karmaşık hale getirip verilerin yorumlanmasını zorlaştırmaktadır. Bu nedenle, bir özet indeksine, özellikle de belirli bir yürüyüş modelinin kalitesinin tek bir ölçüsüne gereksinim duyulmaktadır. YA çalışmalarının verilerinden başlayarak hesaplanabilen ve klinik bir uygulamaya sahip olan birkaç özet ölçüm geliştirilmiştir. Çoğu ölçüt, kinematik YA verilerinden (Normalcy Index, Gait Deviation Index, Gait Profile Score, Movement Deviation Profile); kısmen (Kalça Fleksör İndeksi, $\mathrm{KFI})$ veya tamamen (Yürüyüş Sapma İndeksi, YSi-Kinetik) kinetik verilerden geliştirilmiştir. Diğer taraftan yürüme analizindeki teknolojik yenilikler iki farklı yaklaşıma göre sınıflandırılabilir. Giyilemeyen sensörlere (non-wearable sensors, NWS) veya giyilebilir sensörlere (wearable sensors, WS) dayalı olanlar. NWS sistemleri iki alt gruba ayrılabilir. Görüntü işlemeye (image processing, IP) dayalı olanlar ve zemin sensörlerine (floor sensors, FS) dayalı olanlar. WS sistemlerinde ayaklar, dizler, uyluklar veya bel gibi vücudun çeşitli bölgelerine yerleştirilen sensörler kullanılır. Bunlar arasında ivme-ölçerler, jiroskopik sensörler, manyetometreler, kuvvet sensörleri, ekstansometreler, gonyometreler, aktif işaretleyiciler, elektromiyografi vb. yer alır. Bu derlemenin amacı, yürüme analizindeki son gelişmeleri klinik ve teknolojik yönden incelemek ve ilk olarak klinik açıdan yürüme analizinin verilerinin klinik değerlendirmesine yönelik geliştirilen indeksler ve akabinde yürüme analizi teknolojisindeki son gelişmeleri gözden geçirmektir.

Anahtar sözcükler: yürüme analizi; Gillette yürüyüş indeksi; yürüyüş sapma indeksi; yürüyüş profil skoru; giyilebilir sensörler

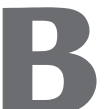

u derlemede yürüme analizindeki son gelişmeler ikiye ayrılarak anlatılmıştır:

I. Yürüme analizi verilerinin klinik değerlendirmesiyle ilgili yenilikler

II. Yürüme analizi teknolojisiyle ilgili yenilikler
There are both clinical and technological innovations in gait analysis (GA). A large number of data and graphics are produced for the evaluation of certain criteria in three-dimensional gait analysis; While this increases the objectiveness of the assessment, it makes the assessment more complex and difficult to interpret. Therefore, there is a need for a summary index, particularly a single measure of the quality of a given gait pattern. A few measurements have been developed which can be calculated starting from the data of GA studies and have clinical applications. These measurements stem from kinematic data (Normalcy Index, Gait Deviation Index, Gait Profile Score, Movement Deviation Profile); partly Hip Flexor Index (HFI) or completely (GDI-Kinetic) kinetic data. On the other hand, technological innovations in analysis can be classified according to two different approaches: non-wearable sensors (NWS) or wearable sensors (WS). NWS systems can be divided into two sub-groups: Based on image processing (IP) and floor sensors (FS). WS systems use sensors placed on various parts of the feet, knees, thighs or waist, such as accelerometers, gyroscopic sensors, magnetometers, sensors, extensometers, goniometers, active markers, electromyography, etc. The purpose of this review is to examine the latest developments in gait analysis from a clinical and technological perspective and first to write indices for the clinical evaluation of gait analysis data from a clinical point of view, followed by the latest developments in gait analysis technology.

Key words: gait analysis; Gillette gait index; gait deviation index; gait profile score; wearable sensors

\section{YÜRÜME ANALIZI VERILERININ KLINIK DEĞERLENDIRMESIYLE ILGILI YENILIKLER}

Tipik bir yürüme analizi (YA) değerlendirme işlemi, hem belirli ölçütlerin (yürüyüş döngüsünün belirli anındaki grafik değerleri, maksimum değerler, hareket aralığı, vb.) hem de özet ölçümlerin (bir hastanın yürüyüş modelinin normallikten sapmasını ölçen birkaç puandan biri) hesaplanmasını içermektedir.

\footnotetext{
- Illetişim adresi: Doç. Dr. Fuat Bilgili, İstanbul Üniversitesi İstanbul Tıp Fakültesi, Ortopedi ve Travmatoloji Ana Bilim Dalı, İstanbul Tel: 0212 - 4142000 e-posta: fuat.bilgili@istanbul.edu.tr 

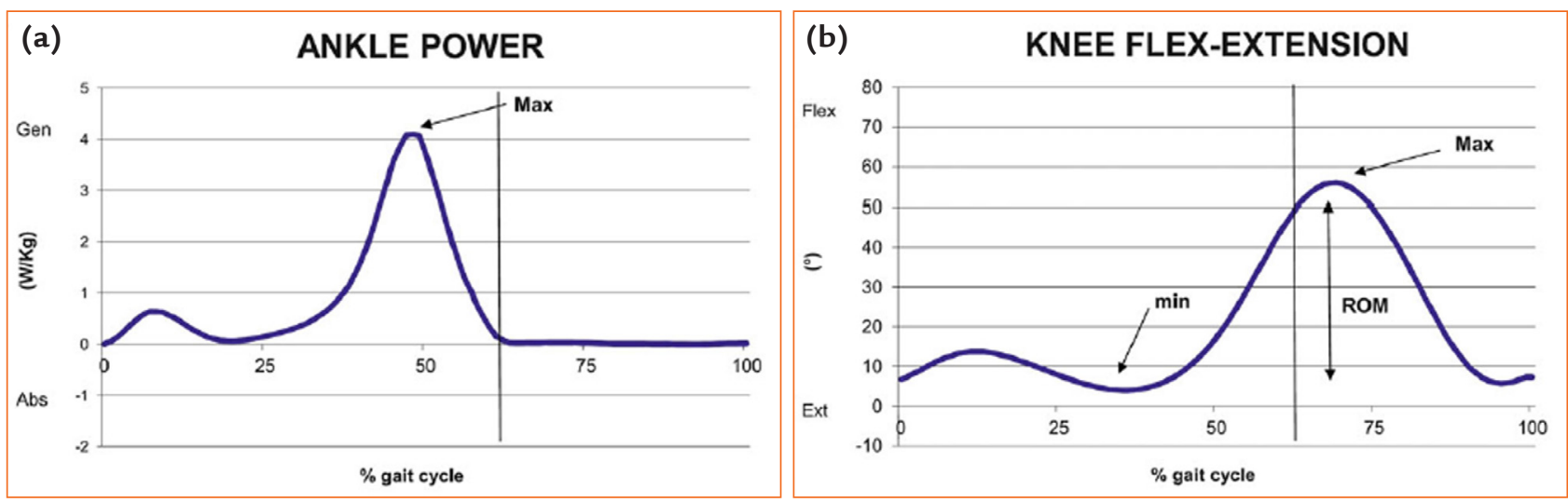

Şekil 1. a, b. Kinetik (a) ve kinematik (b) grafikte tanımlanan belirli parametrelerin örnekleri; ayak bileği güç grafiği (a) ve diz fleksiyon-ekstansiyon grafiği (b).

Belirli ölçütlerin değerlendirilmesine yönelik çok sayıda veri ve grafik üretilir; bu durum bir taraftan değerlendirmenin objektifliğini artırırken diğer taraftan değerlendirmeyi daha karmaşık hale getirip verilerin yorumlanmasını zorlaştırmaktadır. Bu nedenle, bir özet indeksine, özellikle de belirli bir yürüyüş modelinin kalitesinin tek bir ölçüsüne gereksinim duyulması yönünde artan bir farkındalık vardır. ${ }^{[1]}$

Bireyin yürüyüş şeklini ve fizyolojik yürüme performansından sapmalarını açıklamak, önemli olan özelliklerini tanımlamak ve ölçmek için YA grafiklerinde bazı ölçütler kullanılabilir. Özellikle; bazografik, kinematik ve kinetik verilerden başlayarak belirli ölçütler tanımlanabilir: uzaysal-zamansal ölçütler (hız, adım uzunluğu, adım genişliği vb.), yürüyüş döngüsünün belirli bir anında eklem açısı değerleri (kalça hareket açıklığı, orta duruş fazında diz açısının değeri, ilk temastaki ayak bileği açısının değeri, vb.), tepe moment ve güç grafiklerinde tepe değerler (terminal duruştaki dorsi-plantar fleksiyon momentini temsil eden eğrinin mutlak maksimum değer, itme sırasında ayak bileği gücü) (Şekil 1).

Bu hesaplamadan, bir YA raporunun, klinik kullanımı için bazen bir engel olarak görülebilecek çok miktarda veri ürettiğini anlamak kolaydır. Verilerin tekrarlanabilirliğini doğrulamak için her hastada birkaç raporun analiz edilmesi gerektiği düşünülürse, bir YA çalışmasını okumanın ve değerlendirmenin çok zaman gerektirdiği anlaşılır. Klinik ortamlarda bazen hastanın yürüyüşü ile referansın normalliği arasındaki boşluğu kanıtlamak veya bir tedavinin etkinliğini kanıtlamak için basit ve acil bir yönteme sahip olma sorunu vardır. Bu soruna cevap vermek için, yürüme işlevinin basit bir ölçüsünü sağlamak ve böylece bir veya birkaç hastanın yürüyüş modelinin normallikten sapmasını ölçmek için bazı özet ölçümler geliştirilmiştir. Özellikle, bu indekslerin klinik izlenimi somutlaştırmak, normal biçimden yürüme sapmasının derecesini ölçmek, patolojinin şiddetini sınıflandırmak, zaman içinde yürüyüşteki değişiklikleri belgelemek ve rehabilite edici girişimlerinin etkilerini ölçmek için yararlı olduğu ortaya çıkmıştır.

\section{Özet Ölçüler (Summary Measures)}

Literatür, YA çalışmalarının verilerinden başlayarak hesaplanabilen ve klinik bir uygulamaya sahip olan birkaç özet ölçüm önermiştir. Çoğu ölçüm, kinematik YA verilerinden (Normalcy Index, Gait Deviation Index, Gait Profile Score, Movement Deviation Profile); kısmen (Kalça Fleksör İndeksi, KFi) veya tamamen (Yürüyüş Sapma Indeksi, YSi-Kinetik) kinetik ile ilgili YA verilerinden geliştirilmiştir. Aşağıda her parametrenin kısa bir açıklaması, hesaplama için kullanılan veri azaltma tekniği, potansiyel zayıf ve güçlü yönleri, temel klinik ve bilimsel deneyimler verilmektedir.

\section{A. Kinematik İçin Özet Ölçüler}

1. Normalite İndeksi (Ni) (Normalcy Index, NI) ve Gillette Yürüme İndeksi (GYi) (Gillette Gait Index, GGI)

Normalite indeksi (Ni) veya Gillette yürüme indeksi (GYi), genel anlamda yürüyüş modelinin yürüyüş kalitesini açıklamak için tek bir parametreyi tanımlamaya yönelik ilk girişimi temsil eder. ${ }^{[2]}$ Bir hastanın yürüyüş şeklinin sağlıklı bireylerin ortalama yürüyüş modelinden ne kadar farklı olduğunun bir ölçüsüdür ve geliştiriciler tarafından yürüyüş modelinin önemli özelliklerini yakalamak için önemli olduğu düşünülen 16 tek değişkenli yürüyüş parametresinden hesaplanır. Ni, 16 üç boyutlu yürüme analizi (3DGA) değişkenine uygulanan standart çok değişkenli istatistiksel teknikler (temel bileşen analizi) ve özellikle üç uzaysal-zamansal 
ölçüt (duruş fazı yüzdesi, normalleştirilmiş hız ve kadans) ve 13 kinematik ölçüt (ortalama pelvik tilt, pelvik tilt aralı̆̆ı, ortalama pelvik rotasyon, minimum kalça fleksiyonu, kalça fleksiyonu aralığı, salınımda kalça tepe (peak) abduksiyonu, duruş fazında ortalama kalça rotasyonu, ilk temasta diz fleksiyonu, tepe diz fleksiyonu zamanı, diz fleksiyonu aralığı, duruş fazında dorsifleksiyon tepe noktası, salınım fazında dorsifleksiyon tepe noktası ve ortalama ayak ilerleme açısı) oluşturur. Bu 16 bağımsız değişkenin karelerinin toplamı, bireyin yürüyüşünün normalden sapması olarak yorumlanır. Bu istatistiksel yöntemi kullanarak, bir patolojik yürüyüş biçiminin normal bir ortalama profilden sapmasını tek bir sayı olarak ölçmek ve temsil etmek mümkündür. Ortalama değeri 15,7'dir ve yüksek değerler daha anormal yürüyüş şeklini yansıtır.

Normalite indeksi, en çok alıntı yapılan ve doğrulanan özet ölçüdür. Özellikle, kullanımı serebral palsi (SP) ve idiyopatik ayak parmak ucu yürüyen hasta topluluklarında geniş çapta doğrulanmıştır.

Özgün tanıları olan hastaların yürüyüşünü aynı tanıya sahip diğer hastalarla karşılaştırmak, hastaların yürüyüş patolojilerinin gelişimini izlemek veya tedavilerin etkinliğini incelemek için kullanıldığında yararlı olduğu gösterilmiştir. ${ }^{[2-5]}$

Normalite indeksi, çok seviyeli ortopedik cerrahi gibi spesifik tedavilerin, selektif dorsal rizotominin etkilerini ölçmek için sadece çocuklarda değil yetişkinlerde de yaygın olarak kullanılmıştır. ${ }^{[3,6-8]}$ Bununla birlikte $\mathrm{Ni}$, ayak bileği-ayak ortezi (AFO) gibi hedeflenen girişimlerin etkilerini değerlendirirken uygun özgüllüğü ve hassasiyeti göstermediği görülmüştür. ${ }^{[9]}$

Yine de sınırlamaları vardır. Her şeyden önce, indeksi hesaplamak için kullanılan 16 kinematik ölçütün seçimi gelişigüzel görünmektedir ve uzaysal-zamansal ölçütler yürüyüşün değişken olmasıyla karışık bir durum almaktadır. ${ }^{[1]}$

Hesaplaması aslında SP' deki klinik hekimlerin ve uzmanların öznel yargılarına dayanmaktadır. Bu nedenle evrensel olarak mümkün olan en iyi ölçüt belirteci olmayabilir. Ni merkezi sinir sisteminde tümörü olan çocuklar ve ergenler, merkezi sinir sistemi patolojisi tanısı olan yetişkinler ve yetişkin alt ekstremite amputeleri gibi diğer patolojik durumlarda da kullanılmaktadır. ${ }^{[10-12]}$ Ni'nin temel olarak ölçüt seçimi nedeniyle bazı sınırlamalar getirebileceği gösterilmiştir. Ek olarak, seçilen ölçütler yalnızca kinematik değişkenleri içermektedir. Kinetik değişkenlerin dahil edilmesinin tam bir yürüyüş biçimi değerlendirmesi ve planlama için yararlı olduğu iyi bilinmektedir. Üçüncüsü, eğrilerin yalnızca karakteristik noktaları dâhil edilmiştir. Bunların hepsi güçlü bir sınırlama oluşturur.

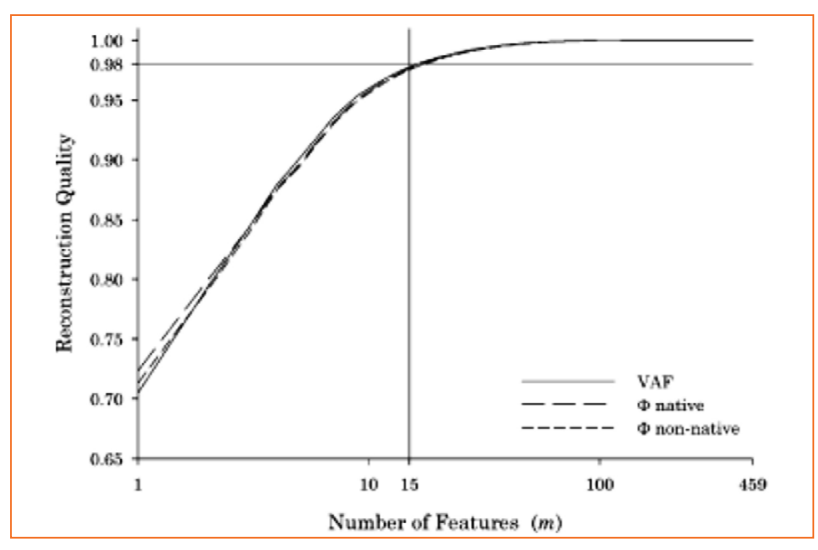

Şekil 2. Tüm verilerin $\% 98$ oranında ilk 15 yürüme özelliğiyle rekonstrükte edilerek verinin azaltılması. ${ }^{[14]}$

Hesaplama yöntemine göre Ni, değişkenlerin her birinde kontrolün ortalamalarını ve varyans değerlerini oluşturmak için aslında güçlü yürüyüş verilerine gereksinim duyar. Laboratuvara özel kontrol verilerine ve minimum numune boyutuna son derece duyarlı olduğu bulunmuştur ve güvenilir bir Ni aracına sahip olmak için kontrol denek verileri gereklidir. ${ }^{[13]}$

\section{Yürüyüş̧ Sapma İndeksi (YSi) (Gait Deviation Index)}

Normalite indeksi sınırlamalarını ele almak için yürüyüş sapma indeksi (YSi) geliştirilmiştir. ${ }^{[14]}$ Genelde YA'da klinik olarak en önemli kabul edilen dokuz eklem açısı için yürüyüş döngüsü boyunca elde edilen verileri kullanır (üç düzlemde pelvis ve kalça, sagittal düzlemde diz ve ayak bileği ve ayak ilerleme açısı). Normalde yürüme analizi grafiğinde 100 noktada eklemlerin açıları hesaplanarak oluşturulur. Verilerin azaltılması amacıyla 51 noktaya normalleştirilmiştir. YA döngüsünün 51 noktasında 9 eklem açısının vektörü hesaplandığında ortaya 9 açı $\times 51$ nokta=459 veri ortaya çıkmaktadır. YSi'de YA ile değerlendirilen büyük bir veri kümesinden, YA kinematiğinden tek değer ayrıştırılarak 15 yürüyüş özelliğinin çıkarılması gerçekleştirilmiştir. Böylece 459/15=30,6 kat data azaltılması sağlanmıştır (Şekil 2). Bir kontrol grubuna uygulanan bu yürüyüş özellikleri, ortalama patolojik olmayan bir yürüyüşü tanımlar. Yürüyüş patolojisi sergileyen bir denek ile kontrol grubu arasındaki 15 yürüyüş özelliğinin kök ortalama kare mesafesi hesaplanır. Elde edilen ölçü normal olarak dağıtılmadığından, logaritması bu şekilde alınmış ve sağlıklı popülasyon için ortalama değer 100 olacak şekilde ölçeklenmiştir. Yüzün altındaki 10 puan, sağlıklı grup ortalamasından bir standart sapmaya karşılık gelir. ${ }^{[14,15]}$ Yürüyüş 
sapma indeksi, $\mathrm{Ni}(\mathrm{r} 2=0,56)$ ile orta derecede korelasyon gösterir; bu iki ölçütün her ikisinin de aynı temel yapının ölçüsü olduğunu düşündürse de, herhangi bir düzeyde geniş bir yayılma, yürüme patolojisinin farklı yönlerini ölçtüğgunü gösterir. [14]

Yürüyüş sapma indeksinin, İşlevsel Değerlendirme Anketi'ne (FAQ, Functional Assessment Questionnaire) göre farklı seviyelerde olan kişilerde normal dağılım gösterdiği ve farklı seviyeler için ortalama değerlerde benzer artışlar olduğu bulunmuştur. YSi'nin geçerliliği ilk olarak sağlıklı ve SP'li bireylerde hem çocuklarda hem de yetişkinlerde değerlendirilmiştir. ${ }^{[14-20]}$ Yetişkinlerdeki YSi, sağlıklı ve SP'li çocuklar üzerinde yapılan çalışmalarda bildirilenlerle dağılım özelliklerinde benzer sonuçlar göstermiştir. ${ }^{[14]}$ YSi artık sadece SP hastalarında değil, Batten hastalığı, kas distrofisi, alt ekstremite amputeleri, Parkinson hastalığı, koksartroz ve romatoid artrit, femur başı epifizi kayması ve lomber spinal stenoz gibi hastalıklarda da uygulanmaktadır. ${ }^{[12,21-29]}$

Normalite indeksi ve YSi yürüme kalitesinin kinematik analizinde tüm değişkenlerin ayrı ayrı anlatılmasından ziyade, tek bir parametre ile belirtilmesi prensibine dayanır. Aralarındaki fark Ni'de, referans veri grubunda oldukça fazla sayıda insan gerektirmesi ve farklı referans veri grupları arasında bu değerlerin önemli ölçüde farklılık göstermesidir. Oysa YSi'nin değerleri referans veri gruplarındaki farklılıklara çok daha az duyarlı görünmektedir. ${ }^{[13]}$ YSi, sıkıştırılırak azaltılmış verilerle yürüyüş sınıflandırması için geliştirilen analitik teknikler temelinde doğal olarak ilerler. [14] Ayrıca daha önce yapılan bir çalışmada GYi değerleri patoloji ile beraber arttığı zaman, GYi üzerindeki belirsizliğin de arttığı gösterilmiştir. Bu, GYi'nin patolojiyle beraber artan GYi değerinde belirsizliğin de artması ve öte yandan YSI'nin varyasyonunun 0'dan 100'e kadar sonlu bir aralıkla sınırlı olmasıyla ilgili olabilir. YSi'nin, her bir eğri için tüm yürüyüş döngüsüne dayalı olması, yürüyüş döngüsü sırasında her eğri üzerinde iyi tanımlanmış ölçütleri kullanan GYI'nin aksine hataların yayılmasını sınırlayabilir. ${ }^{[18]}$

\section{Yürüyüş Profil Skoru (YPS) (Gait Profile Score) ve Hareket Analiz Profili (HAP)}

Yürüyüş profili skoru (YPS), yürüyüş döngüsü boyunca bir kişinin bir tarafının aynı dokuz eklem açısı için hesaplanan verileri ile ortalama normal veriler arasındaki mesafenin doğrudan karekök ortalaması olarak önerilmiştir. Dolayısıyla, YSI'nin altında yatan, mesafe ölçümlerinin daha basit bir yorumunu temsil eder. YPS, özellik analizinden bağımsız olarak hesaplanabilen değiştirilmiş bir ölçümle sonuçlanır. ${ }^{[30]}$ Genel yürüyüş kalitesinin ölçümüne ek olarak, YPS, genel olarak dokuz kinematik değişken (üç düzlemde pelvis ve kalça, sagittal planda diz ve ayak bileği, ayak ilerleme açısı) için yürüyüş değişkenlik skoru (YDS) hesaplamaktadır. YPS genellikle YDS'lerle birlikte bir çubuk grafikte sunulur ve hareket analizi profili'ni (HAP) oluşturur. HAP, yürüyüş döngüsü boyunca ortalaması alınan dokuz ayrı değişkenin sapmasının büyüklüğünü açıklayarak hangi değişkenlerin YPS'deki artışa katkıda bulunduğuna dair içgörü sağlar (Şekil 3).

Yürüyüş profil skoru ve HAP bileşen skorları ile klinisyenlerin kinematik yürüme sapması derecelendirmeleri arasında güçlü pozitif korelasyon bulunmuştur. [30] Böylece bu indekslerin klinisyen yargılarına göre oluşan kriterle geçerliliği olduğuna dair kanıt sağlamıştır. Yazarlar YPS'nin, özellikle HAP'nin, karmaşık kinematik verilerin geleneksel sunumuna ek olarak klinik uygulamada ve eğitimde yararlı olabileceğini öne sürmektedir. Ayrıca, bir girişimin ardından veya zaman içinde hem grubun hem de bireysel sonuçların bir ölçüsü olarak yararlı olabilir. Dolayısıyla, YPS ile birlikte HAP ve YDS bileşenlerinin varlığı, bu özet ölçümün diğer ölçülere göre bir avantajını temsil etmektedir. ${ }^{[30]}$

Yürüyüş profil skoru, YSi $(r=0,995)$ ile çok güçlü doğrusal olmayan bir korelasyon gösterir. Analiz, YPS ile ölçeklenmemiş YSi arasında yakın bir matematiksel ilişki olduğunu göstermiştir. YSi ve YPS aslında aynı temel yapıyı ölçeklendirmenin farklı yollarıdır ve bu nedenle her iki sonuç ölçütünü de kullanmanın pek bir anlamı yoktur. ${ }^{[15]}$ Bununla birlikte, YSi ve YPS'nin klinik uygulama ve araştırmada kullanımı hakkında tartışmalar vardır. Şu anda, her iki indeks için de artılar ve eksiler vardır ve birini diğerinin üzerine seçmek genellikle kişisel tercihlere dayanmaktadır. İki ölçüt arasındaki seçim, öncelikle ölçeklendirilmiş veya ölçeklendirilmemiş bir puanın tercih edilip edilmeyeceği ve HAP'ye atıfta bulunulmasının sonuçların yorumlanmasını geliştirip geliştirmediğiyle ilgilidir. ${ }^{[1]}$ Yakın zamanda SP'li bir grup çocukta YSi ve YPS'nin (YDS'leri ile) değerlendirici içi güvenilirliği ve uyumu araştırılmıştır. ${ }^{[31]}$

Yürüyüş profil skorunun sınırlamalarından biri, YSi'ye benzer şekilde, hesaplamasına hiçbir uzaysalzamansal ölçüt ve kinetiğin dâhil edilmemiş olmasıdır. Uzaysal-zamansal ölçütler için, YPS'ye ek olarak kendi kendine seçilmiş yürüme hızının da rapor edilmesi gerektiğini vurgulamak önemlidir. ${ }^{[15]}$ Bununla birlikte, kinetik için YDS'yi hesaplamakta ilk girişim bazı yazarlar tarafından ayak bileği dorsifleksiyonu, plantar fleksiyon momenti ve ayak bileği gücü için yapılmıştır. ${ }^{[32-34]}$

\section{Hareket Sapma Profili (HSP) (Movement Deviation Profile)}

Karmaşık verilerin geleneksel analizine bir alternatif olarak yapay sinir ağları, kendi kendini organize eden harita (self-organizing map, SOM), çok çeşitli 


\begin{tabular}{|c|c|c|c|c|c|c|c|c|c|c|c|c|c|c|c|c|c|c|c|c|c|}
\hline \multicolumn{22}{|c|}{ Movement Analysis Profile } \\
\hline & & & & \multicolumn{9}{|c|}{ Left } & \multicolumn{9}{|c|}{ Right } \\
\hline & $\begin{array}{l}\text { GPS } \\
\text { Left }\end{array}$ & $\begin{array}{l}\text { GPS } \\
\text { Right }\end{array}$ & $\begin{array}{l}\text { GPS } \\
\text { Overall }\end{array}$ & $\begin{array}{l}\text { Pelvis } \\
\text { Tilt }\end{array}$ & $\begin{array}{c}\text { Hip } \\
\text { Flexion }\end{array}$ & $\begin{array}{l}\text { Knee } \\
\text { Flexion }\end{array}$ & $\begin{array}{l}\text { Ankle } \\
\text { Dors }\end{array}$ & $\begin{array}{l}\text { Pelvis } \\
\text { Obl }\end{array}$ & $\stackrel{\text { Hip }}{\text { Abduct }}^{\text {Hod }}$ & $\begin{array}{l}\text { Pelvis } \\
\text { Rot }\end{array}$ & $\begin{array}{c}\text { Hip } \\
\text { Rotation }\end{array}$ & $\begin{array}{l}\text { Foot } \\
\text { Prog }\end{array}$ & $\begin{array}{l}\text { Pelvis } \\
\text { Tilt }\end{array}$ & $\underset{\text { Flexion }}{\text { Hip }}$ & $\begin{array}{l}\text { Knee } \\
\text { Flexion }\end{array}$ & $\begin{array}{l}\text { Ankle } \\
\text { Dors }\end{array}$ & $\begin{array}{l}\text { Pelvis } \\
\text { Obl }\end{array}$ & $\begin{array}{c}\text { Hip } \\
\text { Abduct }\end{array}$ & $\begin{array}{l}\text { Pelvis } \\
\text { Rot }\end{array}$ & $\begin{array}{c}\text { Hip } \\
\text { Rotation }\end{array}$ & $\begin{array}{l}\text { Foot } \\
\text { Prog }\end{array}$ \\
\hline Median & 10.1 & 11.8 & 11.8 & 8.1 & 10.4 & 12.3 & 3.3 & 5.0 & 3.5 & 6.2 & 14.7 & 17.2 & 7.2 & 12.6 & 17.2 & 12.0 & 5.1 & 6.3 & 5.0 & 3.2 & 21.7 \\
\hline IQR & 0.1 & 1.2 & 0.7 & 0.4 & 0.2 & 0.7 & 0.4 & 0.1 & 0.2 & 0.9 & 0.5 & 0.1 & 1.5 & 2.6 & 3.8 & 3.8 & 0.1 & 0.1 & 1.0 & 0.3 & 1.7 \\
\hline
\end{tabular}
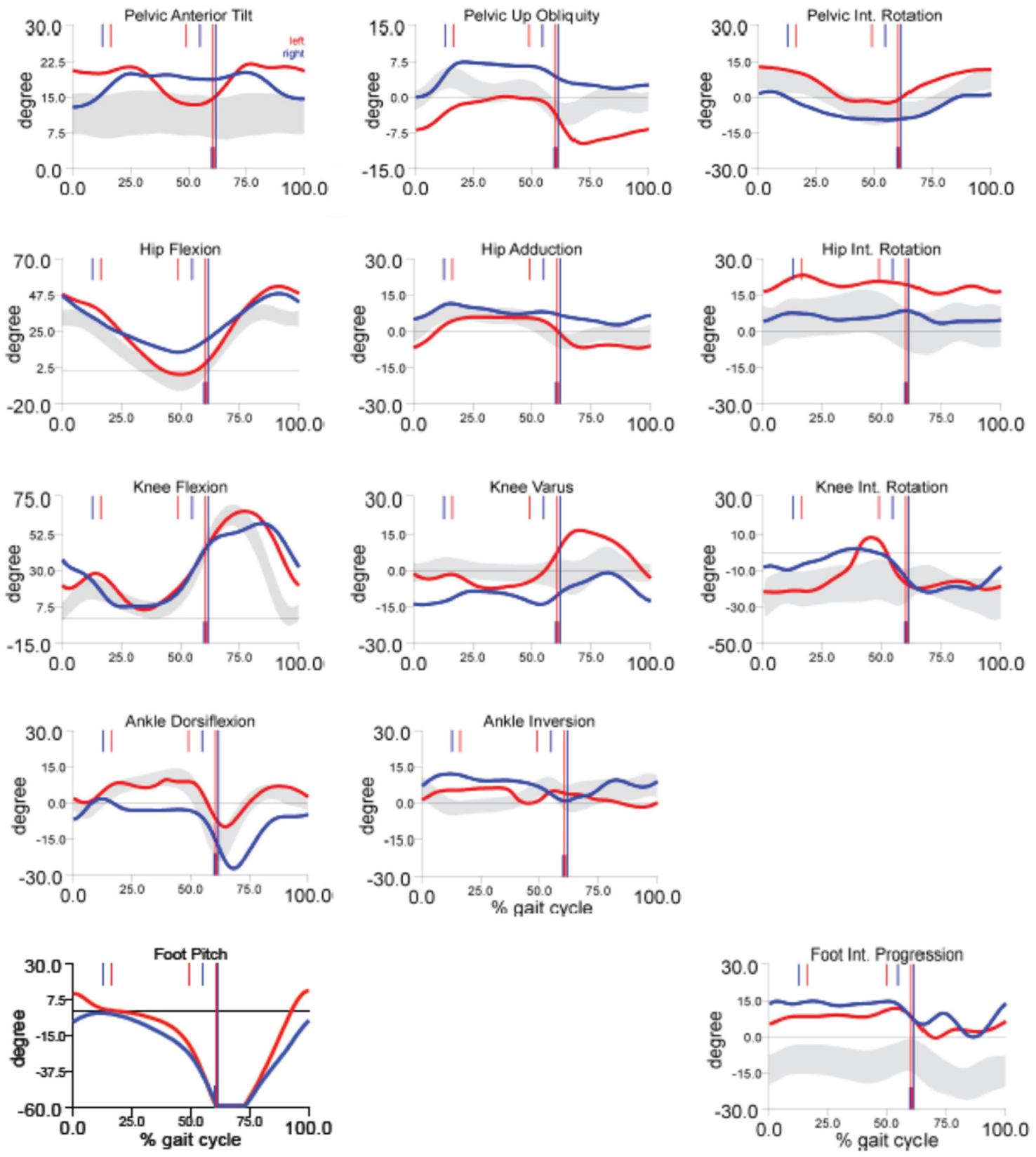

Şekil 3. Yürüme analizi raporunda dokuz kinematik grafiğin her biri tek bir YPS sayısal değeri olarak verilmiş. Sağ ve sol tarafın YPS değerine en fazla etki eden kinematik parametreler, YPS değerlerinin yorumundan grafiği okumadan anlaşılmaktadır. (GPS, YPS; Movement Analysis Profile, Hareket Analiz Profili). 
uygulamalarda normallikten sapmayı tespit etmek için kullanılmıştır. Yürüyüşün normallikten sapmasını ölçmek için SOM'nin niceleme hatasının kullanımı Barton ve ark. tarafından yapılmıştır ve SP'li hastalardan örneklerle gösterilmiştir. ${ }^{[35]}$ Barton ve ark., karmaşık yürüyüş modellerini tek eğriler şeklinde görselleştirmek için yapay sinir ağlarını veya kendi kendini organize eden haritayı (SOM) kullanmıştır. ${ }^{[36,37]}$ SOM, yürüyüş verilerini, toplam veri alanında ilişkisel harita üzerinde düzenlenmiş kök modellere çevirir. Bu yöntem, mevcut yürüyüş şekillerinin tanımlanmasını sağlar ve çok boyutlu veri alanında tanımlanması zor olan yeni yürüyüş şekillerini tanımlamanın yolunu açar. Bu yöntem, girdi verilerinin dikkatli seçilmesiyle kontrol edilebilen bir çözünürlükle tekrarlanabilir boyut azaltımı sağlar. Konuların çok boyutlu sıralanması hem kesitsel hem de boylamsal olarak mümkündür. Bu yöntem, farklı ayak ortezleri arasındaki alt ekstremite koordinasyonundaki farklılıkları belirlemek ve çeşitli yürüyüş problemleri olan bir grup hastada yürüyüş kalitesini değerlendirmek için kullanılmıştır. ${ }^{[35]}$

Hareket sapma profili, potansiyel olarak klinik yorumu destekleyen karmaşık biyomekanik verileri işlemenin alternatif bir yöntemi olarak düşünülebilir. HSP ve YSI'nin yürüme değişikliklerini tespit etme yeteneği SP'li bir çocukta karşılaş̧ıııılmıştır. ${ }^{[38]}$ Sonuç olarak, HSP, yürüyüşteki değişiklikler YSi tarafından gözden kaçırılsa bile değişen yürüyüş şeklini tespit edebilir ve yazarlar, YSI'nin avantajlarını tamamlamak için diğer yürüyüş indekslerinin (örneğin, HSP) ek kullanımını önermektedirler.

\section{B. Kinetik İçin Özet Ölçümler \\ 1. Kalça Fleksör İndeksi (KFi) (Hip Flexor Index, $\mathrm{HFI)}$}

Hesaplamalarında kinetik yürüme analizi (YA) verisi içermeyen önceki özet ölçümlerin sınırlandırılmasından başlayarak kalça fleksör indeksi (KFi) önerilmektedir. KFi, beş kinematik ve kinetik değişkene uygulanan temel bileşen analizi dikkate alınarak geliştirilmiştir. Maksimum pelvik tilt, pelvik tilt aralığı, duruş fazında maksimum kalça ekstansiyonu, kalça fleksör moment eğrisinin ekstansiyondan fleksiyona son geçişinin bulunduğu duruş fazının yüzdesi ve geç duruş fazında tepe kalça fleksör gücü oluşturur. KFi, tek bir anatomik seviyeye, yani kalça eklemine odaklanır; aslında yürüyüş sırasındaki genel kalça işlevini doğru bir şekilde tanımlar. ${ }^{[39]} \mathrm{KFi}$ kalça işlevindeki bir değişikliği nesneleştirmek için kullanıldığından, bu indeksin ana sınırı eklem spesifik olmasıdır; kalça fleksör işlevindeki bir değişiklik, hastanın işlevinde genel bir değişikliği ifade edebilir veya etmeyebilir. Bu nedenle, KFi sadece kalçaya yapılan bir girişimi değerlendirmek için uygundur. ${ }^{[40]}$ Bu ölçütün doğası gereği başka hiçbir uygulama mümkün olmamıştır. Bu nedenlerle literatürde bu indeksi kullanan araştırmacılar sınırıdır ve ağırıklı olarak SP'ye odaklanmıştır. ${ }^{[39,41,42]}$

\section{Yürüyüş Sapma İndeksi-Kinetik (YSi-Kinetik)}

Kalça fleksör indeksi sınırlamasının üstesinden gelmek için YSi-Kinetik geliştirilmiştir. Kinetik değişkenlere dayalı bir indeksi hesaplamak için esasen aynı YSi yöntemlerini kullanır. Yöntem, ham kinetik verilerin \%91 oranında aslına uygun şekilde yeniden yapılandırılmasını sağlayan ilk 20 yürüyüş özelliğinin lineer kombinasyonlarının tekil değer ayrıştırmasını kullanılarak tanımlamıştır. YSi-Kinetik ve YSi doğrusal olarak ilişkilidir, ancak güçlü bir korelasyon göstermez. Bu da yürümenin herhangi bir YSi-Kinetik aşaması için çok değişken kinematik şekillerin olabileceğini ve her bir indeksin yürüyüş patolojisinin farklı bir yönünü ölçtüğünü düşündürür. YSí-Kinetik ayrıca hemipleji tip I-IV, dipleji, tripleji ve kuadriplejide topografik SP sınıflandırmasına dayalı olarak klinik tutuluma göre ölçeklenir. İlginç bir şekilde, hemiplejide, etkilenmemiş uzuv, etkilenen tarafa göre daha düşük YSi-Kinetik skorları sergiler ve bu etkilenmemiş uzuvdaki telafilerin, etkilenen uzuvda gözlemlenenlere göre normal yürüyüşten daha büyük sapmalara neden olduğunu gösterir. ${ }^{[43]}$ YSi-Kinetik, YSi'yi sadece kinematik değil kinetik de dâhil olmak üzere daha kapsamlı bir yürüyüş patolojisi ölçüsü ile tamamlayabilmiştir. Ancak, bilgimiz dâhilinde, literatürde bu indeksin yalnızca birkaç uygulaması mevcuttur. Kiernan ve ark. ${ }^{[44,45]}$, yürüyüş analizi sırasında kalça eklemi merkezini tahmin etmek için rutin olarak kullanılan pelvik anatomiye dayalı farklı regresyon denklemlerinin klinik anlamını araştırmak için YPS ve YSi Kinetik'i kullandı. Başka bir çalışmada, farklı antropometrik setler kullanmanın normal ve diplejik serebral palsi yürüyüşü sırasında tahmin edilen sagittal düzlem momentleri üzerindeki etkisi YSi-Kinetik kullanılarak araştırılmıştır. ${ }^{[46,47]}$

\section{YÜRÜME ANALIZI TEKNOLOJISIYLE ILGILi YENILIKLER}

İnsan yürüyüşünü incelemek için kullanılan bu teknolojik cihazlar iki farklı yaklaşıma göre sınıflandırılabilir: Giyilemeyen sensörler (non-wearable sensors, NWS) veya giyilebilir sensörler (wearable sensors, WS). ${ }^{[48]}$

Giyilemeyen sensör sistemleri, sensörlerin bulunduğu kontrollü araştırma tesislerinin kullanılmasını gerektirir ve denek açıkça işaretlenmiş bir yürüyüş yolunda yürürken, yürüyüşe ilişkin verileri yakalar. Buna karşıık, giyilebilir sensör sistemleri, laboratuvar dışındaki verileri analiz etmeyi ve kişinin günlük aktiviteleri 
sırasında insan yürüyüşü hakkında bilgi almayı mümkün kılar. Her iki yöntemin bir kombinasyonunu kullanan üçüncü bir hibrit sistem grubu da vardır.

\section{A. Giyilemeyen Sensör Sistemleri}

İki alt gruba ayrılabilir: Görüntü işlemeye dayalı olanlar ve zemin sensörlerine dayalı olanlar.

a) Görüntü İşleme Sistemleri: Bir veya daha fazla optik sensör aracılığıyla deneğin yürüyüşü hakkındaki verileri yakalar ve dijital görüntü işleme aracılığıyla farklı ölçütlerin objektif ölçümlerini alır. Analog veya dijital kameralar en çok kullanılan cihazlardır. Lazer mesafe tarayıcıları, kızılötesi sensörler ve uçuş süresi kameraları gibi diğer optik sensör türleri de kullanılır. Bu kategoride iki sistem vardır: işaretli (marker ile) ve işaretsiz (marker olmaksızın).

b) Zemin Sensör Sistemleri: Yürüme bilgisinin, kişinin ayaklarının yere uyguladığı kuvveti ölçen basınç sensörleri ve zemin tepkime kurveti sensörleri (YTK) aracılığıyla ölçüldüğü yürüyüşleri, "kuvvet platformları" adı verilen zeminde yer alan sensörlere dayanmaktadır.

\section{B. Giyilebilir Sensör Sistemleri}

Ayaklar, dizler, uyluklar veya bel gibi vücudun çeşitli bölgelerinde bulunan sensörleri kullanır. İnsan yürüyüşünü karakterize eden çeşitli sinyalleri yakalamak için farklı sensör türleri kullanılır. Bunlar arasında ivme-ölçerler, jiroskopik sensörler, manyetometreler, kuvvet sensörleri, ekstansometreler, gonyometreler, aktif işaretleyiciler, elektromiyografi vb. yer alır.

\section{Yürüyüş Ölçümü İçin Kullanılan Tekniklerin Araştırması}

Yarı öznel tekniklerin aksine, nesnel yürüme analizi teknikleri, çeşitli yürüyüş ölçütleri ile ilgili bilgileri yakalamak ve ölçmek için farklı cihazların kullanımına dayanır. Bu yöntemler üç kategoriye ayrılabilir. Görüntü işleme, zemin sensörleri ve kullanıcılar tarafından taşınan vücut üzerinde bulunan sensörler (giyilebilir sensörler).

Aşağıdaki bölüm, insan yürüyüşü analizi ve tanımada kullanılan en yeni teknolojilerle ilgili bazı çalışmaların derinlemesine bir açıklamasını içermektedir. Yukarıda açıklanan üç kategoriye göre düzenlenmiştir.

\section{Görüntü işleme (Image Processing, IP)}

Tipik görüntü işleme (IP) sistemi, yürüyüşle ilgili bilgileri toplamak için kullanılabilen lensli birkaç dijital veya analog kameradan oluşur. Görüntüleri siyah beyaza dönüştüren eşik filtreleme, açık veya koyu piksel sayısını hesaplamak için piksel sayısı veya görüntünün arka planını basitçe kaldıran arka plan bölümleme gibi teknikler, ölçmek için veri toplamanın olası yollarından sadece birkaçıdır. Bu yöntem, insanları yürüdükleri şekilde tanımlamak için geniş çapta çalışılmıştır. ${ }^{[48]}$

\section{Zemin Sensörleri (Floor Sensors, FS)}

Bu tekniğe dayalı sistemlerde sensörler, zemine "kuvvet platformları" adı verilen veya yürüyüşün basınç veya kuvvet sensörleri ve denek üzerlerinde yürüdüğünde moment transdüserleri tarafindan ölçüldüğü aletli yürüme yolları üzerine yerleştirilir. íki tür zemin sensörü vardır: kuvvet platformları ve basınç ölçüm sistemleri. Kuvvet platformları, basınç merkezini de nicelleştirmelerine rağmen, uygulanan kuwvet vektörünü doğrudan ölçmeyen basınç ölçüm sistemlerinden ayırt edilmelidir. Basınç ölçüm sistemleri, bir ayak altındaki basınç modellerini zaman içinde ölçmek için kullanışlıdır, ancak uygulanan kuwetlerin yatay veya kesme bileşenlerini ölçemez. ${ }^{48]}$

Zemin sensörleri tabanlı sistemlerini IP tabanlı sistemlerden ayıran özellik, yer tepkime kuvveti (YTK) olarak bilinen, yürürken zemine iletilen kuwvetin analizidir. Bu tür bir sistem, birçok yürüme analizi çalışmasında kullanılmaktadır. ${ }^{[48]}$

En karmaşık sistemler, hastanın rahatsızlığı hakkında daha önemli bilgiler elde etmek için ayağın her bölgesinin farklılaştırılmış basıncını zaman içinde ayrı ayrı ölçmeyi mümkün kılan bir sensör matrisine $\left(\mathrm{cm}^{2}\right.$ başına en fazla dört sensör) sahiptir. Bazı ticari kuvvet platformları ve baropodometrik paspaslar:

- Biometrics France'ın OR6-7 AMTI serisi kuvvet platformu

- Farklı tiplerde Kistler kurvet plakaları

- Tecmachine'in dinamometrik matı ADAL

- Tekscan imzalı MatScan Sistemi $(43,6 \times 36,9 \mathrm{~cm})$

- RM Lab tarafindan yapılan yürüyüş matı $(150 \times 50 \mathrm{~cm})$

- RSScan Lab tarafindan üretilen FootScan Plakaları (200×40 cm'ye kadar)

- Zebris tarafindan yapılan duruş ve yürüyüş analizi için FDM-T Sistemi $(150 \times 50 \mathrm{~cm})$

\section{Giyilebilir Sensörler}

Giyilebilir sensörler kullanılarak yapılan yürüyüş analizinde bunlar, insan yürüyüşünün farklı özelliklerini ölçmek için hastanın vücudunun ayaklar, dizler veya kalçalar gibi çeşitli bölgelerine yerleştirilir. Bu, son zamanlarda yapılan birkaç incelemede açıklanmaktadır. ${ }^{[48]}$ Bu bölüm, araştırmada en yaygın olarak kullanılan farklı sensör türlerine kısa bir genel bakış sunmaktadır. Kuvvet sensörleri, ivme-ölçerler, jiroskoplar, ekstansometreler, eğim-ölçerler, gonyometreler, aktif işaretleyiciler, elektromiyografi vb. 


\section{a) Basınç ve Kuvvet Sensörleri}

Kuvvet sensörleri ayağın altındaki YTK'yi ölçer ve ölçülen basınçla orantılı bir akım veya voltaja döndürür. Ancak basınç sensörleri, tüm eksenlerde bu kuvvetin bileşenlerini hesaba katmadan sensöre uygulanan kuvveti ölçer. Bu tipin en yaygın olarak kullanılan modelleri kapasitif, dirençli piezoelektrik ve piezorezistif sensörlerdir. Sensör seçimi, dayanacağı basınç aralığına, doğrusallığına, hassasiyetine ve sunduğu basınç aralığına bağlıdır:

- Rezistif sensörlerde üzerlerine binen ağırlık arttıkça elektriksel dirençleri azalır (Şekil 4).

- Piezoelektrik sensörler: Bu sensörler, üç farklı ortogonal yönde üç deformasyon ölçerden yapılmıştır ve silikon jel üzerine yerleştirilmiştir. Basınç altında jel deforme olur ve ölçüm cihazları bu deformasyonu hesaplar. Deformasyon ölçer ve jel özellikleri biliniyorsa, toplam basınç hesaplanabilir. Bu sensörler mükemmel doğrusallıkları ve reaktiviteleri ile bilinirler, ancak büyük boyutları nedeniyle yüzeylere uyum sağlamazlar.

- Kapasitif sensörler: Bu sensörler, kondenser kapasitesinin iki elektrot arasındaki mesafe dâhil olmak üzere farklı ölçütlere bağlı olarak değişmesi ilkesine dayanmaktadır.

Bu tip sensör, aletli ayakkabılara (Şekil 4) veya baropodometrik tabanlıklara entegre edilerek giyilebilir yürüyüş analiz sistemlerinde yaygın olarak kullanılmaktadır. On iki kapasitif sensör içeren bir iç tabanla elde edilen YTK ölçümlerinin, bir klinik hareket analizi laboratuvarından alınan eşzamanlı ölçümlerle yüksek bir korelasyon gösterdiği bildirilmiştir. Başka bir yenilikçi sistem, yansıtıcı bir malzemenin yakınlığını tespit etmek için yansıyan ışık yoğunluğu kullanılarak oluşturulmuş, normal ve kayma yüklerine duyarlılığı saptanmıştır. ${ }^{[48]}$

\section{b) Eylemsizlik Sensörleri}

Eylemsizlik sensörleri, ivme-ölçerler ve jiroskoplar ve bazen manyetometrelerin bir kombinasyonunu kullanarak bir nesnenin hızını, ivmesini, yönünü ve yerçekimi kuvvetlerini ölçen ve raporlayan elektronik cihazlardır. Bir ivme-ölçer temelde Newton'un Hareket Yasalarının temellerini kullanır. Bu, bir cismin ivmesinin vücuda etki eden net kuvvetle orantılı olduğunu söyler. Orantılılık bölümünü (nesnenin kütlesi) ve tüm kuvvetleri (sensörler ile ölçülen) bilinirse, ivmesi hesaplanabilir. Üç eksenli ivme-ölçerler ve üç eksenli jiroskoplar ile ivme ve açısal hız elde etmek mümkündür. İvmenin integralini alarak hızı elde edilir ve hızı integral alarak üç eksene atıfta bulunulan konumu saptanır. Açısal hızı entegre ederek fleksiyon açısı elde edilir. Böylece, algoritmaları filtreleyerek ve

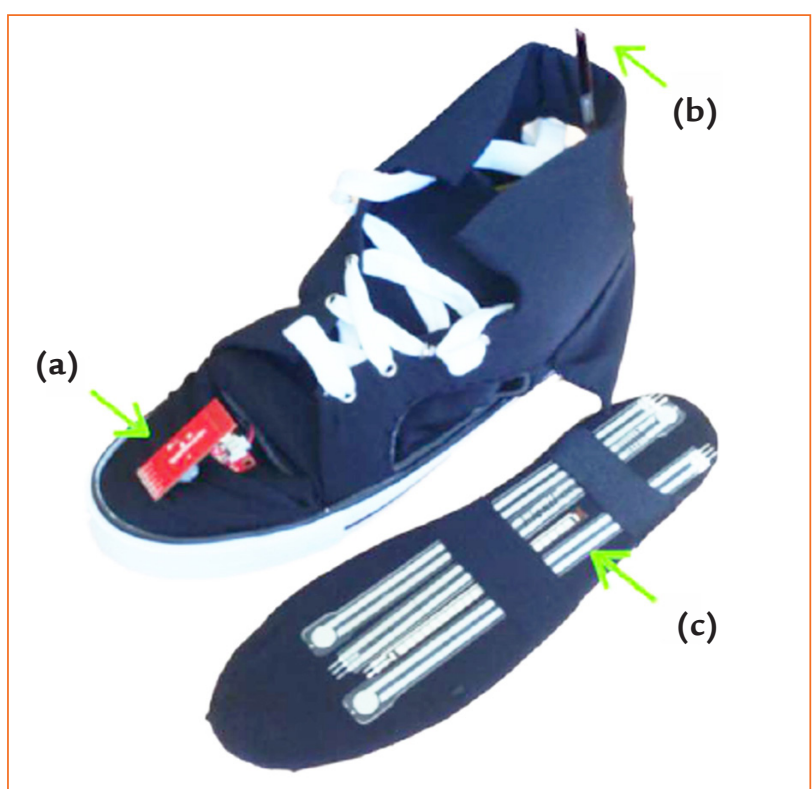

Şekil 4. a-c. Smartxa Projesi'nden aletli ayakkabı: eylemsizlik ölçüm birimi (a); esnek açıölçer (b) ve iç tabanın içinde yer alan basınç sensörleri (c).

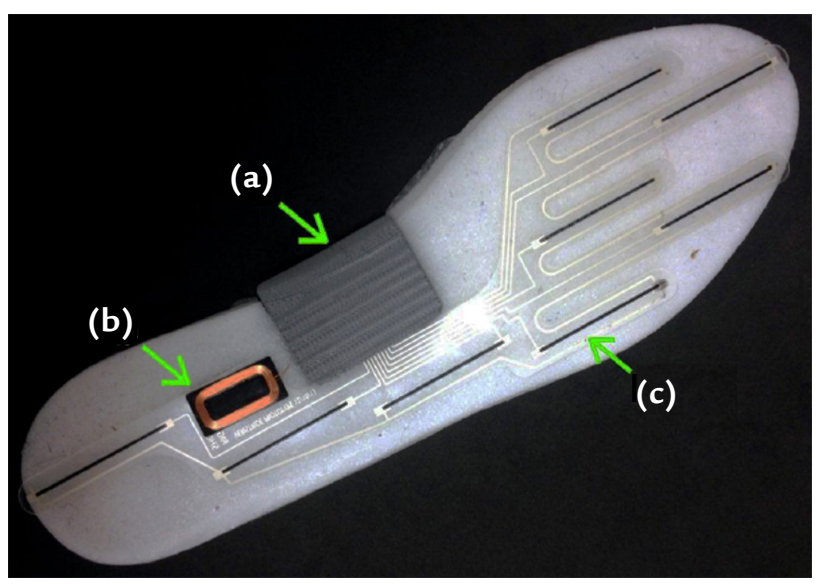

Şekil 5. a-c. Aletli tabanlık; eylemsizlik sensörü (a), indüktif şarj için bobin (b) ve basınç sensörleri (c).

sınıflandırarak ivme-ölçerlerden gelen sinyalleri analiz ederek, belirlenen bir zaman atlamasında atılan adımların sayısını çıkarılabilir. Bu tip sensörler, bir IMU (Inertial Measurement Unit - Eylemsizlik Ölçüm Birimi) cihazına takılabilir.

Eylemsizlik sensörlerinin minyatürleştirilmesi, bunları Bamberg ve diğerleri tarafindan geliştirilen Veristride iç tabanları gibi yürüyüş analizi için aletli tabanlıklara entegre etme olanağını sağlar. Bunlar, ayrıca dağıtılmış plantar kuvvet algılama için özel olarak tasarlanmış basınç sensörleri, bluetooth iletişim modülleri ve bir indüktif şarj sistemi içerir (Şekil 5). 


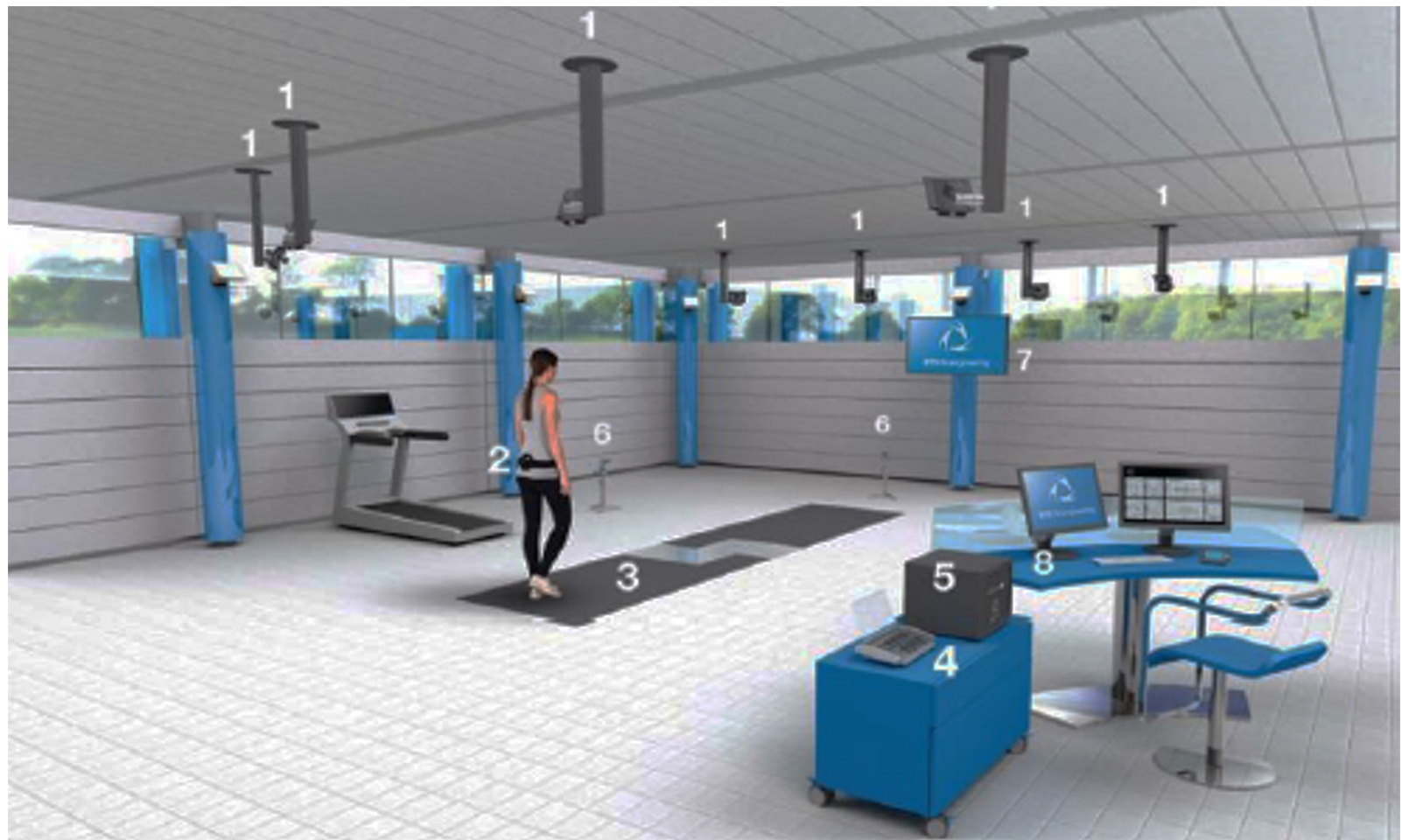

Şekil 6. BTS Yürüme Laboratuvarı kurulumu; kızılötesi video kameralar (1), eylemsizlik sensörleri (2), YTK yürüme yolu ölçümü (3), kablosuz EMG (4), çalışma yeri (5), video kayıt sistemleri (6) ve TV ekranı (7).

\section{c) Gonyometreler}

Bu sensörler ayak bilekleri, dizler, kalçalar ve metatarsal açıları incelemek için kullanılabilir. Gerinim ölçer tabanlı gonyometreler, sensörün ne kadar esnediğine bağlı olarak değişen dirençle çalışır. Esnediğinde, onu oluşturan malzeme gerilir, bu da içinden geçen akımın daha uzun bir yol kat etmesi gerektiği anlamına gelir. Böylece sensör büküldüğünde direnci bükülme açısı ile orantılı olarak artar.

\section{d) Ultrasonik Sensörler}

Yukarıda açıklandığı gibi, analiz edilecek diğer önemli veriler kısa adım ve adım uzunluğu ile ayaklar arasındaki ayırma mesafesidir. Bu ölçümleri elde etmek için ultrasonik sensörler kullanılmıştır. Sesin havada geçiş hızını bilen ultrasonik sensörler, bir nesneye yansıtılırken üretilen dalgayı göndermek ve almak için geçen süreyi ölçer.

\section{e) Elektromiyografi (EMG)}

Elektromiyogram (EMG), kasılan kasın elektriksel bir belirtisidir. Bu istemli veya istemsiz bir kas kasılması olabilir. EMG sinyali, denekten yüzey elektrotları ile non-invaziv olarak ölçülerek veya tel ya da iğne elektrotlarla invaziv olarak ölçülerek elde edilir. Ölçülen sinyal daha sonra güçlendirilir, koşullandırılır ve araştırılan klinik veya bilimsel soruyu yanıtlamak için en uygun formatı verecek şekilde kaydedilir. EMG gibi karmaşık bir analog sinyalin ölçümü ve kaydı karmaşık bir konudur, çünkü ilgilenilen sinyaller her zaman çok küçüktür (bir Volt'un 0,00001 ila 0,005'i arasında). Yüzey elektromiyografisinin (SEMG) uygulanmasının, pasif kastendon özelliklerindeki değişiklikler (periferik, nöral olmayan bileşen), parezi, spastisite gibi yürüme işlevini potansiyel olarak engelleyen ilgili patofizyolojik mekanizmaların invaziv olmayan bir değerlendirmesinde yararlı olduğunu ve işlevsel olarak antagonist kaslarda motor çıktının seçiciliğinin kaybı gösterilmiştir. ${ }^{[48]}$

\section{Ticarileştirilmiş Yürüyüş Analiz Sistemleri ve Laboratuvarları}

Yukarıda bahsedilen sensör ve teknolojilerin farklı kombinasyonlarını kullanan birçok ticari giyilebilir sensör sistemi ve giyilemeyen sensör yürüyüş analizi laboratuvarı vardır. Şekil 6'da gösterilenler gibi laboratuvar veya klinik ortamlarda konumlandırılan ve kalibre edilen NWS sistemlerinin bazı örnekleri: CONTEMPLAS, bir yürüme yoluna dayalı klinik yürüyüş analizi; Tekscan, Pressure Mapping; GRAIL, Gait Real - Motek Medical ve BTS GAITLAB'den time Analysis Interactive Lab. 


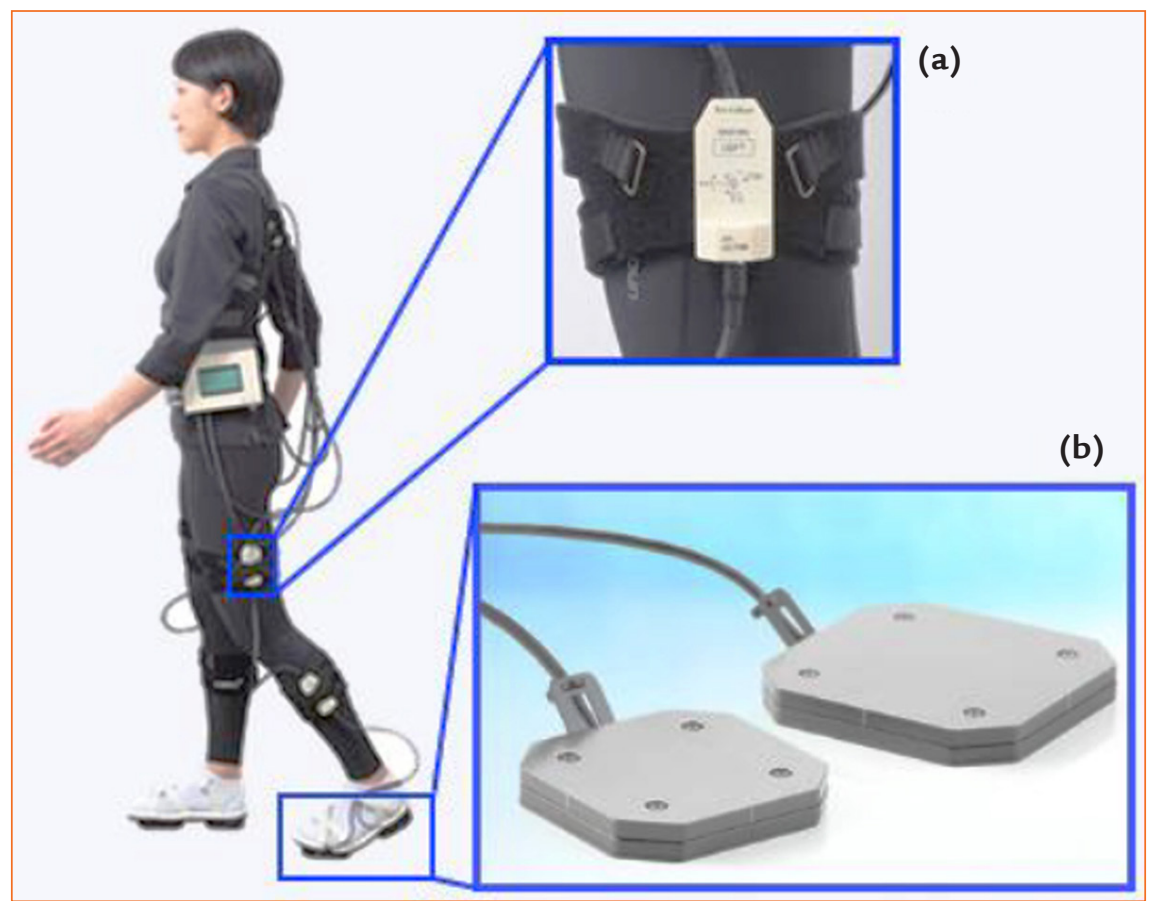

Şekil 7. a, b. Eylemsizlik sensörü (a) ve giyilebilir kuvvet zemini (b) temelli giyilebilir sistem.

Ayrıca, hareket yakalamak için gögüuste, üst ve alt ekstremitelerde yer alan 17 eylemsizlik izleyicisini kullanan ve yaygın olarak kullanılan Xsens MVN gibi giyilebilir sensörlere dayalı başarılı yürüyüş analizi sistemleri ticarileştirilmiştir.

Diğer bir ticari paket ise; alt bacak, uyluk, bel ve sirtta hareket sensörleri ve ayak parmaklarında ve topuklarda giyilebilir kuvvet plakaları kullanan Tec Gihan Co tarafindan geliştirilen kablosuz M3D yürüyüş analiz sistemidir (Şekil 7). M3D kuvvet plakaları (force plate), üç ortogonal eksen boyunca üç bileşenli kuvveti ile üç momenti ölçer. Bir ivme-ölçer, üç eksenli bir jiroskop sensörü ve üç eksenli bir jeomanyetik sensör içerir. Alt extremitelere yerleştirilmiş dokuz eylemsizlik sensöründen ve kablosuz altı eksenli kuvvet sensörlü giyilebilir kuvvet plakalarından oluşan benzer bir kablosuz sistem, insan dinamikleri analizi (IDA) adı altında INSENCO Co. tarafindan sunulmuştur. ${ }^{[48]}$

\section{KAYNAKLAR}

1. Baker R. Measuring Walking: A Handbook of Clinical Gait Analysis. UK: Mac Keith Press; 2013.

2. Schutte L, Stout J, Gage J, Selber P. Poster 29: An index for quantifying deviations from normal gait. Gait Posture 1997;5(2):180. Crossref

3. Domagalska M, Szopa A, Syczewska M, Pietraszek S, Kidon Z, Onik G. The relationship between clinical measurements and gait analysis data in children with cerebral palsy. Gait Posture 2013;38(4):1038-43. Crossref
4. Szopa A, Domagalska-Szopa M, Lasek-Bal A, Zak A. The link between weight shift asymmetry and gait disturbances in chronic hemiparetic stroke patients. Clin Interv Aging 2017;12:2055-62. Crossref

5. Trost JP, Schwartz MH, Krach LE, Dunn ME, Novacheck TF. Comprehensive short-term outcome assessment of selective dorsal rhizotomy. Dev Med Child Neurol 2008;50(10):76571. Crossref

6. Dreher T, Vegvari D, Wolf SI, Geisbüsch A, Gantz S, Wenz W, Braatz F. Development of knee function after hamstring lengthening as a part of multilevel surgery in children with spastic diplegia: a long-term outcome study. J Bone Joint Surg Am 2012;94(2):121-30. Crossref

7. Putz C, Döderlein L, Mertens E, Wolf S, Gantz S, Braatz F, Dreher T. Multilevel surgery in adults with cerebral palsy. Bone Joint J 2016;98(2):282-8. Crossref

8. Thomason P, Baker R, Dodd K, Taylor N, Selber P, Wolfe R, Graham HK. Single-event multilevel surgery in children with spastic diplegia: a pilot randomized controlled trial. J Bone Joint Surg Am 2011;93(5):451-60. Crossref

9. Brehm M-A, Harlaar J, Schwartz M. Effect of ankle-foot orthoses on walking efficiency and gait in children with cerebral palsy. J Rehabil Med 2008;40(7):529-34. Crossref

10. Syczewska M, Dembowska-Baginska B, Perek-Polnik M, Kalinowska M, Perek D. Gait pathology assessed with Gillette Gait Index in patients after CNS tumour treatment. Gait Posture 2010;32(3):358-62. Crossref

11. Cretual A, Bervet K, Ballaz L. Gillette gait index in adults. Gait Posture 2010;32(3):307-10. Crossref

12. Kark L, Vickers D, McIntosh A, Simmons A. Use of gait summary measures with lower limb amputees. Gait Posture 2012;35(2):238-43. Crossref

13. McMulkin ML, MacWilliams BA. Intersite variations of the gillette gait index. Gait Posture 2008;28(3):483-7. Crossref 
14. Schwartz MH, Rozumalski A. The Gait Deviation Index: a new comprehensive index of gait pathology. Gait Posture 2008;28(3):351-7. Crossref

15. Baker R, McGinley JL, Schwartz MH, Beynon S, Rozumalski A, Graham HK, Tirosh O. The gait profile score and movement analysis profile. Gait Posture 2009;30(3):265-9. Crossref

16. Cimolin V, Galli M. Summary measures for clinical gait analysis: a literature review. Gait Posture 2014;39(4):1005-10. Crossref

17. Lee SY, Kwon S-S, Chung CY, Lee KM, Choi Y, Kim TG, Shin WC, Choi IH, Cho T-J, Yoo WJ, Park MS. Rectus femoris transfer in cerebral palsy patients with stiff knee gait. Gait Posture 2014;40(1):76-81. Crossref

18. Massaad A, Assi A, Skalli W, Ghanem I. Repeatability and validation of gait deviation index in children: typically developing and cerebral palsy. Gait Posture 2014;39(1):3548. Crossref

19. McMulkin ML, Gordon AB, Caskey PM, Tompkins BJ, Baird GO. Outcomes of orthopaedic surgery with and without an external femoral derotational osteotomy in children with cerebral palsy. J Pediatr Orthop 2016;36(4):382-6. Crossref

20. Andersson C, Mattsson E. Adults with cerebral palsy: a survey describing problems, needs, and resources, with special emphasis on locomotion. Dev Med Child Neurol 2001;43(2):76-82. Crossref

21. Galli M, Ferrario D, Patti P, Freedland R, Cimolin V, Gavin M, Velinov MT, Heaney G, Brown WT, Albertini G. The use of 3d motion analysis in a patient with an atypical juvenile neuronal ceroid lipofuscinoses phenotype with CLN1 mutation and deficient PPT activity. J Dev Phys Disabil 2012;24(2):155-65. Crossref

22. Eshraghi A, Osman NAA, Karimi M, Gholizadeh $H$, Soodmand E, Abas WABW. Gait biomechanics of individuals with transtibial amputation: effect of suspension system. PLoS One 2014;9(5):e96988. Crossref

23. Galli M, Cimolin V, De Pandis MF, Schwartz MH, Albertini G. Use of the Gait Deviation index for the evaluation of patients with Parkinson's disease. J Mot Behav 2012;44(3):161-7. Crossref

24. Speciali DS, Oliveira EM, Cardoso JR, Correa JC, Baker $\mathrm{R}$, Lucareli PR. Gait profile score and movement analysis profile in patients with Parkinson's disease during concurrent cognitive load. Braz J Phys Ther 2014;18(4):315-22. Crossref

25. Rosenlund $S$, Holsgaard-Larsen A, Overgaard $S$, Jensen C. The Gait Deviation Index is associated with hip muscle strength and patient-reported outcome in patients with severe hip osteoarthritis -A cross-sectional study. PLoS One 2016;11(4):e0153177. Crossref

26. Broström E, Esbjörnsson A, von Heideken J, Larsson $P$, Wretenberg $P$, Iversen M. Change in Gait Deviation Index after anti-tumour necrosis factor- $\alpha$ treatment in individuals with rheumatoid arthritis: a pilot study. Scand J Rheumatol 2013;42(5):356-61. Crossref

27. Esbjörnsson A, Rozumalski A, Iversen $M$, Schwartz $M$, Wretenberg P, Broström E. Quantifying gait deviations in individuals with rheumatoid arthritis using the Gait Deviation Index. Scand J Rheumatol 2014;43(2):124-31. Crossref

28. Caskey PM, McMulkin ML, Gordon AB, Posner MA, Baird GO, Tompkins BJ. Gait outcomes of patients with severe slipped capital femoral epiphysis after treatment by flexion-rotation osteotomy. J Pediatr Orthop 2014;34(7):668-73. Crossref

29. GarbelottiJr SA, Lucareli PRG, RamalhoJr A, de Godoy W, Bernal $M$, Greve JMD. An investigation of the value of tridimensional kinematic analysis in functional diagnosis of lumbar spinal stenosis. Gait Posture 2014;40(1):150-3. Crossref

30. Beynon S, McGinley JL, Dobson F, Baker R. Correlations of the gait profile score and the movement analysis profile relative to clinical judgments. Gait Posture 2010;32(1):129-32. Crossref
31. Rasmussen HM, Nielsen DB, Pedersen NW, Overgaard S, Holsgaard-Larsen A. Gait Deviation Index, Gait Profile Score and Gait Variable Score in children with spastic cerebral palsy: Intra-rater reliability and agreement across two repeated sessions. Gait Posture 2015;42(2):133-7. Crossref

32. Ferreira LAB, Cimolin V, Costici PF, Albertini G, Oliveira CS, Galli M. Effects of gastrocnemius fascia lengthening on gait pattern in children with cerebral palsy using the gait profile score. Res Dev Disabil 2014;35(5):1137-43. Crossref

33. Firth GB, Passmore E, Sangeux M, Thomason P, Rodda J, Donath S, Selber P, Graham HK. Multilevel surgery for equinus gait in children with spastic diplegic cerebral palsy: medium-term follow-up with gait analysis. J Bone Joint Surg Am 2013;95(10):931-8. Crossref

34. Rutz E, Baker R, Tirosh O, Romkes J, Haase C, Brunner R. Tibialis anterior tendon shortening in combination with Achilles tendon lengthening in spastic equinus in cerebral palsy. Gait Posture 2011;33(2):152-7. Crossref

35. Barton G, Lisboa P, Lees A, Attfield S. Gait quality assessment using self-organising artificial neural networks. Gait Posture 2007;25(3):374-9. Crossref

36. Barton G, Lees A, Lisboa P, Attfield S. Visualisation of gait data with Kohonen self-organising neural maps. Gait Posture 2006;24(1):46-53. Crossref

37. Barton GJ, Hawken MB, Scott MA, Schwartz MH. Movement Deviation Profile: A measure of distance from normality using a self-organizing neural network. Hum Mov Sci 2012;31(2):284-94. Crossref

38. Barton GJ, Hawken MB, Holmes G, Schwartz MH. A gait index may underestimate changes of gait: a comparison of the Movement Deviation Profile and the Gait Deviation Index. Comput Methods Biomech Biomed Engin 2015;18(1):57-63. Crossref

39. Schwartz $\mathrm{MH}$, Novacheck T, Trost J. A tool for quantifying hip flexor function during gait. Gait Posture 2000;12(2):122-7. Crossref

40. Novacheck TF, Trost JP, Schwartz MH. Intramuscular psoas lengthening improves dynamic hip function in children with cerebral palsy. J Pediatr Orthop 2002;22(2):158-64. Crossref

41. Choi SJ, Chung CY, Lee KM, Kwon DG, Lee SH, Park MS. Validity of gait parameters for hip flexor contracture in patients with cerebral palsy. J Neuroeng Rehabil 2011;8(1):1-7. Crossref

42. Lee KM, Chung CY, Kwon DG, Han HS, Choi IH, Park MS. Reliability of physical examination in the measurement of hip flexion contracture and correlation with gait parameters in cerebral palsy. J Bone Joint Surg Am 2011;93(2):150-8. Crossref

43. Rozumalski A, Schwartz MH. The GDI-Kinetic: a new index for quantifying kinetic deviations from normal gait. Gait Posture 2011;33(4):730-2. Crossref

44. Kiernan D, Hosking J, O'Brien T. Is adult gait less susceptible than paediatric gait to hip joint centre regression equation error? Gait Posture 2016;45:133-6. Crossref

45. Kiernan D, Malone A, O'Brien T, Simms CK. The clinical impact of hip joint centre regression equation error on kinematics and kinetics during paediatric gait. Gait Posture 2015;41(1):175-9. Crossref

46. Kiernan D, Walsh M, O'Sullivan R, O'Brien T, Simms CK. The influence of estimated body segment parameters on predicted joint kinetics during diplegic cerebral palsy gait. J Biomech 2014;47(1):284-8. Crossref

47. Cimolin V, Galli M, Vimercati SL, Albertini G. Use of the Gait Deviation Index for the assessment of gastrocnemius fascia lengthening in children with Cerebral Palsy. Res Dev Disabil 2011;32(1):377-81. Crossref

48. Muro-de-la-Herran A, Garcia-Zapirain B, Mendez-Zorrilla A. Gait analysis methods: an overview of wearable and nonwearable systems, highlighting clinical applications. Sensors (Basel) 2014;14(2):3362-94. Crossref 